\title{
서평: T. Foken, Micrometeorology, Springer, 2008, 306pp., ISBN: 978-3-540-74665-2
}

\author{
홍 진 규* \\ 연세대학교 대기과학과/지구환경연구소 \\ (2009년 3월 3일 접수; 2009년 3월 13일 수정; 2009년 3월 13일 수락)
}

\section{Book Review: T. Foken, Micrometeorology, Springer, 2008, 306pp., ISBN: 978-3-540-74665-2}

\author{
Jinkyu Hong* \\ Department of Atmospheric Sciences/Global Environment Lab, Yonsei University, Seoul, Korea 120-749 \\ (Received March 3, 2009; Revised March 13, 2009; Accepted March 13, 2009)
}

현재 기후변화와 그에 따른 우리 생활의 변화와 관 련하여 다양한 분야에서 다양한 담론들이 쏟아지고 있 다. 그러나 이러한 다양한 담론을 뒷받침하는 과학 연 구의 최전선은 역시나 육상 및 해양 생태계와 토양 내에 서식하는 동식물, 그리고 인간이 방출하거나 흡 수하는 온실 기체나 에너지의 교환량을 장기적으로 감 시하는 것이라 할 수 있다. 이러한 교환량을 감시하는 데 있어서 미기상학적 방법(micrometeorological technique)은 농림기상학, 생태학이나 환경 공학, 그리 고 도시 공학연구자들에게 연구 도구의 하나로서 오랫 동안 사용되어 왔으며, 최근 들어서는 우리나라뿐만 아니라 전세계적으로 다양한 분야에서 기후 변화가 인 류의 삶과 생태계에 미치는 영향을 진단 평가하기 위 한 다양한 목적을 위하여 미기상학적 측정 방법을 사 용하고 있다.

하지만 실제로 이러한 미기상학적 방법을 응용하고 적용하는데 있어서 미기상학을 전공하지 않는 사람들 에게 필요한 기본적인 미기상학 지식을 비교적 간단하 고 명쾌하게 소개하는 지침서는 부족한 것이 사실이다. 이러한 점에서 이 책의 저자가 서문에서 밝히고 있듯 이 응용적인 측면에서 미기상학적 지식을 필요로 하는 사람들에게 이 책은 기본적인 지식, 관측적인 측면, 수치 모형의 측면을 고루 균형 있게 다루고 있는 책
이라고 말할 수 있겠다. 하지만 이러한 사실은 역으로 책 제목과는 다르게 미기상학이 전체적으로 다루고 있 는 대기 경계층 상부의 구조나 구름과의 상호 작용, 대류 경계층, 야간 경계층 및 자세한 난류 구조에 관 한 지식을 원하는 연구자에게는 적합한 책이 아닐 수 있음을 시사한다.

이 책은 8 개의 장과 1 개의 부록으로 이루어져있다. 1 장에서는 미기상학의 역사와 미기상학이 다루는 작은 규모의 현상들을 기상학에서 다루어지는 현상들의 시 공간 규모의 입장에서 설명하고 미기상학이 다양한 응 용 분야를 갖는 이유를 설명한다. 그리고 지표면의 직 접적인 영향을 받는 대기 경계층의 기본적인 특성과 지표면에서의 복사 수지, 에너지 수지와 물수지의 기 본적 특성에 대해서 간단히 설명한다.

2장과 3장은 미기상학에서 가장 중요한 현상인 난류 의 특성에 대해서 다룬다. 보통 난류 문제는 미기상학 을 이해하고자 하는 다른 분야의 연구자들이 가장 어 렵게 생각하는 분야이며 이 책에서도 자세하고 복잡한 수식의 유도 과정은 다루지 않았다. 2장은 주로 난류 운동방정식에 관한 설명과 대부분의 관측이 이루어지 는 지면 부근의 지표층(surface layer)의 대기 흐름을 설명하는 이론인 Monin-Obukhov 상사 이론(similarity theory), 그리고 난류의 에너지 스펙트럼을 다룬다.

* Corresponding Author : Jinkyu Hong (jkhong@yonsei.kr) 
3장에서는 지면의 특성을 표현하는 몇 가지 모수들 (예, 거칠기 길이, 영면 변위)의 물리적 의미, 지면 특 성 변화가 대기 흐름에 미치는 영향, 관측 타워의 발 자국 분석 그리고 군락 하부의 난류의 특성에 관한 최신 연구 내용을 소개한다. 실무적인 입장에서 측정 방법에 대한 빠른 이해를 원하는 사람이라면 2장에서 는 2.3절과 2.4절을 3장에서는 3.1절과 3.4절, 3.7절 에 집중하는 것이 바람직할 것으로 생각된다. 만약 군 락이 높이가 큰 산림에서의 관측을 시도하려는 연구자 에게는 거칠기층(roughness sublayer)에 관한 내용을 다루는 3.5.3절의 내용도 눈 여겨봐야 할 것이다. 그 리고 지표면 에너지 수지를 다루는 연구자라면 3.7절 의 내용은 간단하지만 유용한 정보를 제공한다.

4장은 에너지 및 물질 교환량을 측정하는 다양한 미기상학적 방법을 설명하며, 응용적인 측면에서 중요 한 정보를 제공한다. 최근 각광받고 있는 에디 공분산 방법과 함께 보웬비 방법이나 공기역학적 방법과 같이 대기의 연직 구조 측정을 활용하는 방법, 그리고 에디 축적 방법과 플럭스-분산 방법에 대해서 설명한다. 특 히 에디 공분산 방법을 다루는 4.1절에서는 실제 에디 공분산 방법을 적용하여 연구자들이 원하는 최종의 플 럭스값을 만들어내기 위해서 필요한 일련의 과정들 (예, 좌표 변환 과정, 관측 기기의 한계로 인해 발생 하는 주파수 반응 보정, 밀도 보정)과 함께 자료의 품 질 관리와 결측 자료 메우기에 대하여 간단하게 설명 하고 있다. 환경 오염의 측면에서 화학물질의 교환량 을 다루려는 연구자들에게는 4.5 절을 참고하는 것이 바람직하다.

5장은 지표층에서 일어나는 에너지와 물질 교환 중 에서 특히 증발량에 초점을 맞추어 모형을 이용한 방 법론에 대해서 설명한다. 이 곳에서 언급되고 있는 모 형은 일반적인 대기 중규모 모형에서 흔히 사용되는 수치 모형뿐만 아니라 간단하게 가능 증발량을 계산하 는 수식까지도 포함한다. 유명한 Penman-Monteith 복 합 방정식이나 큰에디 모사(large-eddy simulation)도 간단하게나마 다루고 있다. 하지만 전반적으로 직접 모형을 이용하여 증발량을 추정하고자 하는 연구자들 에게는 이곳의 내용만으로는 실질적인 도움을 받기 어 려울 것으로 생각된다. 그리고 광합성 과정을 통한 탄 소와 물 순환 연결성과 탄소 순환의 모델링에 관한 언급을 통해 생지화학 순환과 기후 변화의 연관성을 보여주는 노력이 없는 것이 아쉽다.
6장에서는 다시 측정 방법론으로 돌아온다. 이 장 은 저자가 지적한 것처럼 기상 측기를 다루는 책들을 찾아보기 어려운 현실에서 간단하고 유용한 정보를 제 공하고 있다. 관측 기기를 사용하는데 필요한 자료 집 록의 원칙, 신호 추출, 기기의 특성을 나타내는 시간 상수에 정보를 제공한다. 그리고 복사계, 풍속계, 온습 도계, 우량계와 같은 직접 관측기기의 원리를 소개함 과 동시에 SODAR(Sonic detecting and ranging), Scintillometer와 같은 원격 탐사 관측 장비도 함께 소개한다. 자료 품질 관리에 관한 내용도 보이는데 실 제로 적용할 때 필요한 정보는 이 장에 언급되어 있 는 정보만으로는 충분하지 않다.

7장은 몇 가지 미기후학적인 측면에서 미기상학적 현상들을 설명하고 있는데, 저자가 지적한 것처럼 이 곳의 설명은 매우 일반적인 내용만 간단히 설명하고 있다. 두 페이지 분량의 산곡풍이나 해륙풍 설명은 상 식 수준의 언급에서 그치고 있는 것은 이들 현상의 중요성이나 다른 장의 자세한 설명에 비추어밨을 때 조금 아쉽다. 이 책의 전반적인 내용의 흐름상 다른 내용과 연결 고리가 부족하며, 단기간 내에 실제 미기 상학 방법을 적용할 때는 필요성이 덜한 내용이다.

8장에서는 다양한 분야에서 적용되는 미기상학 이론 들의 예들을 설명한다. 대기 오염 확산 문제, 풍력 에너지 활용, 소음 공해 문제와 생물 기상학에서 적용 할 수 있는 미기상학 지식들에 대해서 설명하고 있다. 이 책의 독일어 판에는 독일 사정에 맞는 보다 다양 한 예제들이 있다고 하는데 영어판에서는 몇 가지 예 로 제한되어 설명되어 있다. 부록에서는 참고할만한 다른 서적이나 미기상학에서 많이 쓰이는 상수들과 몇 가지 일반적인 관계식들에 관한 설명, 용어 정리를 볼 수 있다.

전반적으로 이 책은 미기상학에서 다루는 전체 대기 경계층 중에서 가장 활발한 물질 및 에너지 교환이 일어나며 대부분의 직접 관측이 이루어지는 지면 근처 의 지표층의 현상들을 다루고 있다. 특히 30 여년 동안 현장 관측에서 얻어진 저자의 경험과 자료는 이 책의 가장 큰 장점이라고 할 수 있겠다. 또한 실질적으로 미기상학 지식 없이 미기상학적 방법을 적용하려는 연 구자들에게 빠른 시일 내에 유용한 정보를 제공하는데 훌륭한 교재가 될 수 있을 것으로 생각된다. 하지만 미기상학 측정을 하는데 있어서 어느 정도 필요한 측 정 이론, 수치 모형 방법론, 관측 기기 이론, 난류 현 
상들과 같은 다양한 주제를 포괄적으로 다룸으로 인하 여 체계적이고 보다 완성도 있는 설명은 조금 부족한 것이 아닌가 싶다. 그리고 모형이나 인공 위성 자료를 활용하는 방법론을 원하는 연구자에게는 적절한 정보 를 제공하지는 않는다. 하지만 저자가 책의 몇몇 곳에 서 지적한 것처럼 보다 깊은 내용을 원하는 연구자들 에게는 이 책에서 언급하고 있는 주요 논문들과 책들 이 주요한 지침서가 될 것이다. 저자가 제시한 책과 일부 중복되기도 하지만 아래의 책들은 이러한 내용을 채워주는데 훌륭한 책들이 될 것이다.

1) 기상 측기:

Brock F. V. and S. J. Richardson, 2001. Meteorological Measurement Systems, Oxford University Press, 290 pp.

Kaimal J. C. and J. J. Finnigan, 1994. Atmospheric Boundary Layer Flows: Their structure and measurement, Oxford University Press, 289 pp.

2) 난류 이론:

Stull, R. B., 1988. An Introduction to Boundary Layer
Meteorology, Kluwer Academic Publishers, 666pp.

Garrat, J. R., 1992. The atmospheric boundary layer, Cambridge University Press, 316 pp.

3) 미기상학 측정 이론:

Lee, X., W. Massman and B. Law, 2004. Handbook of Micrometeorology, Kluwer Academic Publisher, 250pp.

4) 일반적인 미기상학 및 미기후학적 지식:

Oke, T. R., 1987. Boundary layer climate, $2^{\text {nd }}$ Edition, Routledge, 435pp.

Arya, S. P., 2001. Introduction to Micrometeorology, Academic Press, $2^{\text {nd }}$ Edition, 420pp.

윤진일, 1999. 농업기상학, 대우학술총서, 338pp

\section{감사의 글}

본 연구는 21 세기 프론티어 연구개발사업인 수자원 의 지속적 확보기술개발 사업단의 연구비지원(과제번 호: 1-8-3)으로 수행되었다. 